\title{
LA IDEA DE PERSONA MORAL Y JURÍDICA EN EL REALISMO METAFÍSICO*
}

\author{
Juan Omar Cofré Lagos **
}

\begin{abstract}
RESUMEN
En este trabajo nos proponemos explicar, desde una perspectiva iusfilosófica, la evolución y la relación entre el concepto jurídico y el filosófico de "persona". Examinamos brevemente el origen y la evolución que esta noción ha tenido en la tradición occidental, y la idea que de ella ha elaborado el iusnaturalismo para sortear la objeción positivista, de acuerdo con la cual el concepto de persona es exclusivamente una construcción jurídica, que nada tiene que ver con el concepto metafísico o existencial de persona, entendido como hombre o ser humano. Después de examinar el realismo metafísico clásico y moderno, nos inclinamos por entender el concepto de persona desde una perspectiva lógico-semántica, siguiendo la doctrina de G. Frege.
\end{abstract}

PERSONA - IUSNATURALISMO - REALISMO METAFÍSICO

\section{The idea of the moral and legal person in metaphysical realism}

\section{ABSTRACT}

In this paper we intend to explain from a legal-philosophical perspective, the evolution and the relationship between the legal concept and the philosophical concept of "person". We briefly examine the origin and the evolution that this notion has had in western tradition, and the idea that legal naturalism has elaborated to sort out the positivist objection related to the fact that the concept of person is exclusively a legal construction that has notbing to do with the metaphysical or existential concept of person, understood as human being. After examining classical and modern metaphysical realism, we inclined towards understanding the concept of person from a logical-semantic perspective, following G. Frege's doctrine.

PERSON - LEGAL PHILOSOPHY - METAPHYSICAL REALISM

* Este trabajo es producto del Proyecto FONDECYT No 1040116, denominado "Fundamentación filosófica de la dignidad humana".

** Doctor en Filosofía, Profesor de Filosofía del Derecho en la Universidad Austral de Chile, Valdivia, Chile. jcofre@uach.cl. Trabajo recibido el 28 de marzo de 2008 y aceptado para su publicación por el Comité Editorial el 24 de octubre de 2008. 
a pregunta fundamental que articula este trabajo interroga acerca de si la idea jurídica de "persona" se explica, determina y agota exclusivamente en las relaciones jurídicas producto de la legislación humana o si, por el contrario, hay una realidad metafísica o antropológica anterior con la cual aquélla mantiene una relación conceptual necesaria.

El trabajo explora los siguientes aspectos:

i) referencias al origen del concepto "persona"

ii) idea de "persona" en la filosofía antigua y medieval

iii) idea de "persona" en Kant

iv) el problema jurídico

v) la reconstrucción del realismo metafísico de "persona"

vi) una interpretación desde la teoría lógico-lingüística de Frege

\section{INTRODUCCIÓN}

Desde el punto de vista jurídico, "persona” y "sujeto de derecho" son sinónimos estrictos. ${ }^{1}$ Para Kelsen, por ejemplo, la "persona” es el centro de imputaciones, a partir del cual se articula un complejo normativo de derechos y obligaciones. Esta noción de persona supone un constructo normativo totalmente independiente de la persona, en cuanto realidad óntico-antropológica. Esta tesis antimetafísica es compartida, con mayor o menor intensidad, por muchos juristas. En otros términos, el positivismo sostiene que entre el concepto jurídico y filosófico de persona no hay relaciones necesarias y ni siquiera relevantes para el derecho.

Para comenzar, hay que reconocer que los argumentos que se suelen ofrecer para sostener esta tesis son razonables, bien articulados y consistentes desde el punto de vista positivista, pero, a nuestro modo de ver, no lo suficientemente sólidos y convincentes como para desestimar la tesis contraria que sostiene, precisamente, que el concepto de persona elaborado por el derecho se enraíza esencial y necesariamente en la ontología y la antropología metafísica, de acuerdo con las cuales existe un núcleo óntico irreductible, radical y común entre la idea filosófica y la jurídica de persona.

Realizados los análisis de rigor, concluimos que conviene entender la idea de persona en dos sentidos distintos, pero con una sola referencia o denotación, inspirándonos

${ }^{1}$ En el contexto de este trabajo, cuando hablamos de "persona" nos referimos exclusivamente a la persona física y excluimos, naturalmente, a la persona jurídica. Esto, porque, como se verá, el concepto que verdaderamente encierra un problema de carácter óntico no es el de "persona jurídica", sino el de persona, en un sentido antropológico y, por consecuencia, en un sentido jurídico.

Nosotros hemos explicado la diferencia que existe entre los objetos jurídicos -que constituyen sus propias reglas de derecho- en virtud de su naturaleza y los que son creaciones del legislador. Los primeros dan origen a las reglas óntico-regulativas, mientras los segundos nacen a la vida jurídica en virtud de las reglas constitutivas. Cfr. "Las Reglas Óntico-constitutivas, Fundamentos de la Persona y la Dignidad Humana". Revista de Derecho. Universidad Austral de Chile, Vol. XV, diciembre 2003, pp. 37-58. 
en la semántica contemporánea y, muy especialmente, en la de uno de sus fundadores, Gottlob Frege, quien ha distinguido en la estructura interna de la expresión el sentido de la denotación.

\section{i) Referencia al origen del concepto "persona"}

Para contribuir a comprender qué debe entenderse por "persona" en la esfera de lo jurídico, comenzaremos por explicar a grandes rasgos -en lo esencial y relevante para este trabajo- qué y cómo se ha entendido este concepto central en la tradición filosófica, esto bajo la convicción de que ésta ha contribuido a fundamentar la idea jurídica de persona y que, en último término, hay una línea continua entre la noción filosófica y la jurídica.

Como es bien sabido, los griegos no tuvieron un concepto claro y consciente de persona, aunque es posible sorprender algunos atisbos en Platón y Aristóteles. Sin embargo, distinguieron entre "ánthropos" (lat. "homo”) y "prósopon” (lat. "persona”). Este último término viene del teatro y significa "máscara”, tanto en el sentido teatral -la figura que representa un rostro humano- como del hombre que se oculta tras ella. El actor enmascarado es, pues, "alguien" que se persona o apersona por intermedio de la máscara. Es decir, la máscara deviene, en definitiva, en el rostro del hombre que se aparece, muestra y actúa primero en el tablado y en el "escenario de la vida" -por decirlo metafóricamente- después.

\section{ii) Idea de "persona" en la filosofía antigua y medieval}

Probablemente con el humanismo estoicista, ${ }^{2}$ la idea de "prósopon" se acerca más al concepto latino "persona". Esto, porque -como se sabe- los estoicos, sobre la base del racionalismo clásico, destacaron los rasgos universales y propiamente humanos que intrínsecamente pertenecen a toda entidad del género "homo sapiens", más allá de las etnias, culturas, y de la condición que a cada hombre le ha tocado en suerte asumir y vivir en una comunidad.

Como es de suponer, estos conceptos hicieron crisis cuando aparece el cristianismo e introduce la extraña -para una mentalidad todavía racionalista y realista como lo eran la helenística y la latina- concepción de las tres entidades divinas que, siendo distintas, tienen una naturaleza común y, más aún, el caso del Hijo que posee una doble naturaleza: humana y divina a la vez.

Para comprender esta complejidad real y conceptual, el pensamiento cristiano recurrió al concepto griego de ousía (lat. "sustantia") que quiere decir, en el lenguaje natural, "aquello que se posee", "lo" que se tiene, pero también "lo" que es universal y común a todos los individuos de la misma especie; esto es, en el sentido aristotélico, "sustancia segunda" o "esencia” (gr. "tó ti en éinai"). Algunos pensadores cristianos concluyeron

${ }^{2}$ Cfr. Fassó, G., "El estoicismo. Naturaleza, razón y ley”, en Historia de la filosofía del Derecho, Vol. 1, Pirámide, Madrid, 1982, pp. 78 y ss. 
que el concepto de "hipóstasis" era más adecuado para expresar la sustancia divina que el término "prósopon”, que siempre recordaba la idea de "máscara” y "teatralidad”, ya que conllevaba la noción de "comunidad". De modo, pues, que las personas divinas fueron entendidas más bien como "hipóstasis" que como "prósopon”. Pero este último concepto permaneció, sobre todo, para expresar lo propio y privativo del hombre, no tanto su racionalidad sino, más bien, en su intimidad. "Persona" llamaron los Padres latinos, precisamente, al hombre en cuanto portador de un centro de interés propio e individual. San Agustín, con su filosofía intimista y confesional, resaltó aún más este aspecto, opuesto a la idea de exterioridad, más propia de la filosofía griega. ${ }^{3}$ Lo íntimo -el mundo interior- es lo propio de los individuos humanos y es, en su intimidad, donde el hombre se encuentra y dialoga consigo mismo y se distingue de toda alteridad. Por la intimidad se diferencian unos hombres de otros y cada cual adquiere su personalidad. Quien no sea capaz de construir intimidad, no podrá tampoco elaborar una personalidad y, con ello, instalarse no simplemente como hombre sino, esencialmente, como persona en el mundo social y espiritual.

Sobre la base de estas ideas de carácter filosófico y teológico, Occidente va construyendo, siglo tras siglo, ideas más complejas del hombre que rebasan la clásica idea griega para acuñar, definitivamente, la idea de "persona". La persona no es sólo un animal racional sino, además, debe reconocerse como un ente dotado de una cierta alcurnia y singularidad, que no se encuentra en ningún otro ser de la creación. Boecio, heredero de la tradición metafísica y cristiana, concibió la persona como "sustancia individual de naturaleza racional", con lo cual vino a decir que el hombre no es solamente esencia sino que es, principalmente, esencia en la existencia, es decir, sustancia pensante y racional.

En otros términos, cuando preguntamos acerca de "qué es" este ente y contestamos "un hombre", estamos denotando su esencia, pero si preguntamos de este hombre "quién es", y se nos contesta "Sócrates", estamos refiriéndonos a su sustancia, es decir, su persona. La persona es la plenitud del ser; en cuanto "hombre", denota una abstracción, en cambio, "persona" hace referencia a un existenciario y, puesto que el ser es más perfecto en la existencia que en la abstracción o en la ficción, entonces la persona es plenitud de existencia humana, y también el ente más perfecto y sublime, máxime si, además, cuenta entre sus notas esenciales la racionalidad, en el sentido griego, y la posibilidad de la vida eterna en la doctrina cristiana.

Todo cuanto llevamos dicho resume -seguramente de manera imperfecta- la idea filosófica y teológica clásica (antigua y medieval) de persona, pero poco dice aún de la idea moderna y laica, de trascendental importancia para la acuñación jurídica de esta idea en el campo del derecho. Habiendo muchísimo que decir, nos permitimos distinguir solamente dos líneas de pensamiento, propias de la modernidad y esenciales para la construcción moderna y contemporánea del concepto de persona.

\footnotetext{
${ }^{3}$ San Agustín desarrolla la idea de persona especialmente en De Trinitate, VII, 6. Cf. Ferrater Mora, J., Diccionario de Filosofía, Alianza Editorial, Madrid, 1982, Vol. 3, pp. 2551-2552, y Abbagnano, N., Diccionario de Filosofía. Fondo de Cultura Económica, Buenos Aires, México, 1982, pp. 909-910.
} 
La Edad Media, en su momento de madurez cultural, puede entenderse como una sociedad universal habitada por hombres que compartían básicamente y sin problematicidad el mismo repertorio de creencias religiosas, humanas y divinas. El Humanismo primero y el Renacimiento, después, traen consigo una crisis a las instituciones culturales (especialmente, teológica y filosófica) legadas por el Medioevo que aparecen y desarrollan concepciones de mundo que contradicen abiertamente los dogmas de la llamada República cristiana. ${ }^{4}$ La idea del pueblo de Dios como un todo anónimo y silencioso, que se deja conducir colectiva e indiferenciadamente por la Iglesia hacia la salvación, es motivo de sospecha primero y, después, de abierta rebelión en los escritos y en la obra de los primeros reformistas. Lutero será uno de los primeros hombres modernos que reclamará enérgicamente la autonomía de la conciencia individual a la hora de relacionarse con Dios. ${ }^{5}$ El hombre tiene unos derechos de autodeterminación de su conducta religiosa, en virtud de un don que le ha sido dado por el Creador y que ha quedado inscrito en su misma naturaleza. Dios, hacedor del hombre, hace al hombre libre, de modo que la libertad no depende de autoridades humanas, sino que ésta, que tiene origen divino, define también esencialmente la condición humana y el puesto del hombre en el cosmos. El hombre, justamente porque es libre (y racionalmente libre) y es persona, está consciente de sus actos y puede, por sus propios medios, buscar y encontrar a Dios en la intimidad de su conciencia. Nace así el individualismo -extraño al Medioevo-, tan característico del hombre moderno; implica autonomía de la voluntad y capacidad para que cada persona ordene y regule su vida religiosa (y civil), en la intimidad de su conciencia, y pueda construir su propio proyecto de vida conforme a su libertad.

El otro hito importante, en la construcción de un concepto más amplio y rico de persona, lo constituye el racionalismo moderno, representado paradigmáticamente por la filosofía cartesiana. En sus Meditaciones metafísicas, Descartes describe el proceso intelectual que lo condujo a abandonar metódicamente todas sus "antiguas opiniones" - es decir, la filosofía aristotélico-tomista- para reivindicar categóricamente la autarquía de la razón a la hora de construir el conocimiento.

De este modo, el pensamiento adquiere independencia total y se libera de toda autoridad, con lo cual se refuerza y enriquece la idea de "hombre" como un individuo autovalente, determinado única y exclusivamente por su propia capacidad racional, lo que le otorgará independencia y legitimará su autonomía religiosa, filosófica y jurídica en el mundo político y social.

Y aunque es verdad que Descartes no destaca la intimidad de la conciencia en el sentido espiritual en que después lo hará Pascal, sí que sienta las bases para considerar, más tarde, que la persona humana, en tanto racional sometido a sus propias leyes, puede -y tal vez debe- desempeñar el rol de ser su propio legislador -en materia moral-, sustra-

${ }^{4}$ Cfr. Fassó, G., Historia de la filosofía del Derecho, Vol. 2, Ediciones Pirámides, S.A., Madrid, 1982, pp. 15-16.

${ }^{5}$ Cfr. Whittaker, E., "La Reforma y el Nacimiento del Estado Moderno", Historia del Pensamiento Económico. F.C.E. México, D.F., Buenos Aires, 1948, pp. 44-52. 
yéndose así, como se observa en Kant, a las inclinaciones de la naturaleza y autocausando su propia causalidad conforme a las leyes universales de la libertad.

\section{iii) Idea de "persona" en Kant}

Con todo, no quedaría ni siquiera medianamente edificado el concepto de "persona" que estamos construyendo a la luz de la historia de las ideas si no incorporáramos al análisis -aunque sea brevemente- y no integráramos la idea de "persona" tal cual es elaborada por el pensamiento de Kant. Lo notabilísimo de Kant es la afirmación y descripción de la persona en cuanto ente moral. La moralidad es la pieza central de su filosofía práctica y, a la luz de esa idea, hay que entender la conciencia como el núcleo central de la persona humana y fuente de su dignidad. ${ }^{6}$

Kant distingue dos grandes esferas de la realidad: el mundo de la naturaleza y el mundo de la libertad. La persona humana está determinada -en su realidad sustancialcorporal- por las leyes de la naturaleza, lo mismo que cualquier otro ente del mundo material. En el mundo natural rige el principio de causalidad, de modo que un efecto está siempre determinado por su causa pero, además, hay que distinguir el mundo de la libertad. En este mundo actúa la persona racional, no en cuanto ente natural sino en cuanto yo puro, es decir, en cuanto mera conciencia, sustraído enteramente al dominio impuesto por la corporeidad o naturaleza. Desde este punto de vista el hombre, o mejor, la persona, al mirarse a sí mismo se encuentra con un hecho evidente, puro y simple, indubitable y radical, la conciencia del deber o moralidad. Ésta mueve a la voluntad a actuar en una determinada dirección por puro respeto al deber. La persona humana se siente responsable de su deber, de lo cual se sigue que es, además y primordialmente, libre. Kant postula la libertad como una condición necesaria que, aunque no se puede demostrar teóricamente, es esencial para comprender la moralidad. Sin libertad no habría moralidad y el hombre quedaría determinado por las leyes de la causalidad, al igual que cualquier otro ente de la naturaleza. Y si eso fuera así, carecerían de sentido la eticidad y la juridicidad que encuentran su fundamento en el mandato del deber.

Por moralidad - dice Kant- no solamente nos vemos elevados a la condición de "hombres" sino también a la de "personas". No solamente a la de "sujetos" (entidades meramente contrapuestas a los objetos en la relación cognoscitiva), sino también a la condición de personas especialmente revestidas de excelsitud y, por ende, tan disimétricas frente a todo lo demás en el mundo, como por encima de él. ${ }^{7}$

A la luz del aporte kantiano proponemos redefinir el concepto de persona bajo los siguientes términos: sustancia individual consciente, dotada de razón y voluntad. Es sustancia, porque no se puede concebir la persona sino como un ente que es aquí y ahora, y que existe de manera única e indivisa, de modo tal que resulta absolutamente

${ }^{6}$ Especialmente relevante para comprender la esencia del pensamiento moral kantiano es su famosa obra Fundamentación de la metafísica de las costumbres. Espasa Calpe, duodécima edición, Madrid, 1996.

${ }^{7}$ Cf. Díaz, E., "Persona", en 10 Palabras claves en Etica. Adela Cortina (ed.). Editorial Verbo Divino, Navarra, 1994. 
incomunicable. La persona requiere de su constante actualidad para mantenerse en la existencia y si no se mantiene, deja de ser persona. Esta sustancia es, además, racional, como hemos dicho. Esto significa, desde el punto de vista práctico, que está capacitada para examinar los actos propios y ajenos, y juzgar que éstos y aquéllos se ajustan o no a los fines que, conforme a la naturaleza humana, vale la pena conseguir. Y si estos fines -y los medios mediante los cuales se accede o pretende acceder a ellos- son compatibles con los que manda la razón, podría decirse que son buenos y justos.

Pero una cosa es que los entes y acciones que se muestran al examen de la razón -o, si se quiere, de la racionalidad-sean buenos o malos en sí mismos, y otra, muy diferente, es que se quieran o no se quieran. Quien quiere o no quiere, quien busca o evita la consecución de un fin, es la voluntad. La razón muestra el acto actual o virtual como bueno o malo, como justo o injusto, pero no nos mueve a conquistarlo o evitarlo; el cometido queda entregado a la voluntad. Esto es lo que en la filosofía clásica se entiende por "boúlesis", la apetencia conforme a la razón que la distingue de la apetencia sensible o mero deseo. La voluntad en sí misma no es racional ya que actúa conforme a la razón, mientras que el mero deseo actúa sin sujeción alguna a la razón, de suerte que si hacemos el bien por mero deseo, lo hacemos también por casualidad, no de modo racionalmente concordado. La razón examina y emite un juicio y la voluntad elige conseguir o rehusar, es decir, actúa libremente.

Nace así la libertad en el agente moral que es la persona humana. La libertad, que es el ejercicio de la voluntad conforme a la luz de la razón, es, en consecuencia, pura y únicamente de la persona. No hay otro ser en la tierra que sea capaz de autodeterminar sus actos y decidir actuar conforme a su decisión. Gracias a la libertad, el hombre puede superar la causalidad, ponerse al margen de ella y, de ese modo, resistir y vencer las inclinaciones, como el deseo ciego, la fuerza de los instintos y la pasión. En ese sentido, Kant ha entendido a la persona como ser racional sometido a las leyes morales que se da a sí mismo, lo que no significa que sean arbitrarias, ya que entonces carecerían de racionalidad en la medida en que racionalidad y universalidad se implican mutuamente.

Ciertamente Kant reconoce que la persona, jurídicamente hablando, es un sujeto cuyas acciones son imputables, ${ }^{8}$ pero considera que más allá de ello la persona humana, por ser esencialmente un núcleo de conciencia moral, sometido a las exigencias del deber, es también una realidad filosófica y real que actúa, bajo determinadas condiciones de legalidad, en la sociedad. Por eso, según este autor, la persona humana sólo a través de la historia de la especie puede realizar su naturaleza, que es la libertad de autoproyectarse con su razón para sí y para la sociedad civil que está fundada por completo en el derecho. No hay, en consecuencia, en el pensamiento iusfilosófico de Kant, una abstracción formalista de la "persona" sino, más bien, una completa integración que recoge los elementos -que en el curso de la historia fue acuñando la filosofía prácticay los integra y coordina adecuadamente en una nueva concepción en la que el hombre aparece como un ser extraordinariamente diferente de todos los demás, en virtud de su conciencia que lo abre al mundo como un ser que no puede eludir su responsabilidad

\footnotetext{
${ }^{8}$ Cfr. La metafísica de las costumbres, op. cit., p. 30.
} 
frente a sí mismo y a los otros, sin violentar su preclara conciencia del deber, esto es, su moralidad y su juridicidad.

En síntesis, todo derecho y toda moral, desde el punto de vista filosófico, están fundados en el supuesto de que la persona es un ser responsable y, precisamente, porque es esencialmente responsable, es también libre y debe responder por lo que hace, no debiendo hacerlo, o por lo que no hace, debiendo hacerlo. La persona es, pues, esencialmente, sustancia consciente dotada de racionalidad, de voluntad y, en consecuencia, capaz de actuar no condicionadamente por las leyes de la naturaleza o inclinaciones emanadas de su corporeidad, sino en virtud de su intrínseca libertad. Toda esta complejidad real hace esencialmente de la persona humana un ser con dignidad. Así, pues, como la racionalidad es la nota relevante del hombre en la idea griega, la dignidad será el atributo fundamental de la persona en la filosofía medieval y moderna.

\section{iv) El problema jurídico}

Como vimos, los latinos tradujeron la expresión griega "prósopon” por "persona" y le otorgaron a este término un sentido más amplio que incluía no sólo al personaje de ficción sino, también, la posición del hombre en la sociedad. La idea subyacente parece ser la siguiente: así como el actor se manifiesta en la ficción como personaje, así también el hombre participa en el mundo social representando o asumiendo un papel, es decir, actúa como persona. De ahí, entonces, la analogía que se puede observar entre homo y persona, por un lado, y actor y personaje, como observa I. M. Hoyos, ${ }^{9}$ por otro.

Ahora bien, el hombre en cuanto "animal político" queda naturalmente integrado a la sociedad y participa bajo alguna condición o estado. Su participación consiste esencialmente en un modo de actuar. Su actuación queda sometida al conjunto de disposiciones jurídicas que le obligan o le permiten participar en la vida social de una determinada manera y, en este sentido, viene a ser, jurídicamente hablando, no simplemente "homo" sino "persona", es decir, sujeto de derecho.

De acuerdo con los juristas latinos, la persona, en primer lugar, las cosas y las relaciones después, constituyen el centro del derecho, de suerte que el elemento primordial de la legislación y del derecho, como arte o ciencia de "lo justo", versa sobre la persona. ${ }^{10}$ Esta versión latina es totalmente compatible con la idea contemporánea que de la persona han elaborado el derecho constitucional y el derecho internacional de los derechos humanos. En efecto, en estos ordenamientos jurídicos el concepto de persona es la pieza clave y fundamental sobre la cual giran todos los principios y las disposiciones de orden constitucional e internacional. El desarrollo de los pormenores de este concepto, en estas áreas del derecho, daría origen a extensos desarrollos que, por la índole de este trabajo, no pueden tener cabida aquí.

${ }^{9}$ De la dignidad y los derechos humanos. Editorial Temis S.A., Bogotá, 2005, p. 5.

${ }^{10}$ Cfr. Fassó, G., Historia de la filosofía del Derecho, Pirámide, Madrid, 1982. Vol. 1, Cap. 8, "La jurisprudencia romana”, pp. 101-115. 
La persona o sujeto de derecho puede entenderse como titular de derechos y obligaciones, como sujeto capaz de asumir derechos y obligaciones o, incluso, como ambas cosas a la vez. Bien, ¿qué significa ser titular o capaz de derechos u obligaciones? La ciencia jurídica ha respondido a esta pregunta pero, más allá de la pregunta $-y$ de la respuesta- subyace una cuestión filosófica de la mayor importancia y que, otra vez, separa radicalmente las concepciones del derecho en dos posiciones, al parecer, incompatibles. Ciertamente, nos podemos acercar a la problemática por otro costado, preguntando si la persona (como entidad jurídica) es anterior al derecho o si es una consecuencia de éste. Si es anterior, entonces hay que reconocer una primacía óntica que obliga al legislador y, como dato primero y fundamental, es causa y razón de ser del derecho. Y si, por el contrario, la persona es una construcción de la cultura, y en este campo específico un producto de la legislación, entonces el jurista puede ignorar cualquier supuesto metafísico u ontológico subyacente y atender únicamente los datos objetivos y formales que emanan de la norma jurídica. Y si esto fuera así, la norma jurídica y la noción puramente jurídica de persona seguirían siendo el centro esencial de preocupación de la ciencia del derecho, como quiere Kelsen.

Pero hay más problemas implicados. En el fondo, en este replanteamiento reaparece la vieja e irreductible oposición entre "naturaleza" ("physis") y "convención" ("nómos"). Si la persona es ante el derecho y no por el derecho, se podría hablar de derechos naturales o de derechos humanos esenciales inherentes al hombre -como de hecho predican numerosos tratados internacionales sobre derechos humanos y diversas constituciones, incluida la chilena- o, en otros términos, de derechos inalienables que bajo ningún respecto, legislación ni régimen político alguno podría desconocer. Y si no fuera así, y la persona efectivamente fuera una consecuencia normativa, un mero concepto jurídico y no una realidad, quizá podríamos estar facultados para pensar que, en esas condiciones, los derechos humanos ya consagrados en la cultura jurídica contemporánea dependen de la voluntad del constituyente, del legislador o del arbitrio del gobernante. Conocemos la enorme polvareda que este problema ha levantado en la filosofía y en la teoría del derecho pero, por no constituir el centro de nuestros intereses en este trabajo, lo pasaremos por alto. Con todo esto queremos decir que vale la pena adentrarse, aunque sea introductoriamente, en el problema iusfilosófico que plantea la noción de persona, comenzando por exponer y analizar brevemente algunas ideas propias del positivismo, para luego ahondar en una teoría no positivista que, en nuestra opinión, debería contribuir -aunque sea muy modestamente- a explicar y a enriquecer la idea de persona humana tal como debe ser entendida en el derecho.

Tomemos como punto de referencia, y tal vez como paradigma positivista, el influyente pensamiento de Kelsen en esta materia. En lo sustancial, el autor vienés sostiene que hay una diferencia esencial entre el concepto de hombre y el de persona. ${ }^{11}$ No se trataría, en este último caso, de un concepto que recoge e integra la irrupción

${ }^{11}$ Cfr. Teoría pura del derecho. UNAM, México D.F., 1981, pp. 198 y ss., y también Teoría general del derecho y del Estado. UNAM, México D.F., 1995, pp. 110 y ss. 
en el terreno jurídico de una realidad sustancial y real, sino todo lo contrario. Kelsen comienza apoyándose en la distinción filosófica - tan característica del empirismo inglésde Berkeley, quien rechaza la idea clásica de sustancia por considerar que se trata de una pura construcción mental que carece de consistencia en sí misma. De este modo, “cualidades empíricamente observables son también interpretadas como atributos de un objeto o de una sustancia, y que gramaticalmente se presentan como predicados de un sujeto. Esta sustancia no es una entidad adicional. El sujeto gramatical que la denota es únicamente -dice el jurista- un símbolo para expresar el hecho de que las cualidades forman una unidad". ${ }^{12}$

Sobre esta base filosófica Kelsen sostiene que la persona física no es una realidad natural, sino una construcción del pensamiento jurídico. La persona -como sujeto de deberes y derechos- no es, entonces, el ser humano, aunque la conducta de éste constituya el contenido de esos deberes o el objeto de tales derechos; en otras palabras, el sujeto de derecho es la personificación de esos derechos y deberes. Definir, por tanto, la persona como un ser humano es incorrecto, porque el hombre y la persona no son solamente dos conceptos heterogéneos, sino también el resultado de puntos de vista enteramente distintos. Lo acertado de la afirmación, según él, se pone en evidencia si se observa que el hombre está sometido al orden jurídico solamente con respecto a ciertas acciones y omisiones específicas, mientras que respecto a todas las demás no se encuentra en relación con el orden jurídico. En consecuencia, "el concepto de persona física o natural no es otra cosa que la personificación de un complejo de normas jurídicas. El hombre, como hombre individualmente determinado, es sólo el elemento que constituye la unidad en la pluralidad de las normas". 13

Si el derecho es pura forma y la forma viene dada por el entramado normativo, entonces "persona" no puede sino tener un sentido abstracto y genérico y, más precisamente, vendría a ser un concepto instrumental que recoge e integra relaciones que vienen dadas y determinadas por el sistema normativo. Luego, no hay que confundir al hombre, en tanto realidad biológica y física, con la persona física, aunque el adjetivo pueda inducir a error. La persona, para la teoría pura, es el centro de un complejo normativo, una suerte de haz, facultado por otras normas jurídicas, para asumir derechos y obligaciones. "La concepción kelseneana de persona - escribe I. M. Hoyos- insiste en una idea que no debo dejar de resaltar: la persona es la unidad de personificación de un conjunto de normas y esa unidad no se explica por la facticidad ni tampoco por una dimensión jurídico-natural del hombre, sino por el hecho de que una norma le otorga al ser humano carácter jurídico". ${ }^{14}$

Desde este punto de vista, hay una diferencia clara en los atributos del hombre en cuanto hombre, y los atributos de la personalidad en cuanto sujeto capacitado por el orden jurídico para actuar en la malla político-social. Esta concepción de la persona

\footnotetext{
12 Op. cit., p. 109.

13 Op. cit., p. 112.

${ }^{14}$ Hoyos, I. M., De la dignidad y de los derechos humanos. Editorial Temis, Bogotá, 2005, p. 9.
} 
asume (interpretamos), al parecer, que hay una diferencia relevante entre la realidad que representa el concepto y el concepto mismo en tanto realidad mental. Si distinguimos, entonces, entre el concepto objetivo y el concepto mental -o, si se quiere, entre la materia objetiva del concepto y su forma mental- encontramos una diferencia esencial, la misma que se puede derivar al confundir lo que es el contenido de un concepto con las formas que ese concepto adopta para determinar el contenido. El error de la ciencia jurídica está, según Kelsen, en confundir una vez más los contenidos con la forma de los contenidos. Desde el punto de vista filosófico y antropológico el hombre es una realidad material aprehendida intelectivamente como concepto. De modo que al concepto de "hombre" expresado por la palabra hombre, responde una denotación o referencia real que corresponde a los seres humanos. En el caso del concepto "hombre", encontramos efectivamente atributos empíricos más allá del orden lingüístico y conceptual, pero no ocurriría lo mismo con el concepto de "persona”, tal cual aparece y se lo usa en derecho. El concepto de "persona" no tiene una realidad en sí mismo, independientemente de la norma jurídica que lo nomina; agota su existencia en la mera realidad formal y eso es lo que capta y expresa correctamente la teoría pura. Ni siquiera se puede concebir a la persona (jurídica) como titular de derechos subjetivos, si por esto se quiere decir que hay o existen derechos que el sujeto puede accionar desde su interioridad. Eso sería caer también en un realismo, aunque subjetivista, que estaría tan extraviado como el realismo objetivista.

Tanto en la doctrina de Kelsen como en la de Ihering, Ferrara, ${ }^{15}$ Demogue, Recasens Siches ${ }^{16}$ y muchos otros juristas se mantiene firmemente la idea de que el concepto de persona se puede reducir enteramente a términos jurídicos. Esto implica que hay que entender esta importante noción tan sólo como una realidad formal sin contenido óntico. De este modo, se esfuma la idea boeciana de persona como sustancia o existente individual, y se destruye la supuesta unidad real y teórica que existiría entre el concepto filosófico y el concepto jurídico de persona.

Esta teoría supone desconocer la necesaria relación -explícita en la tradición jurídica antigua- que se cree existe entre la realidad humana y la jurídica. Cuesta pensar en dos órdenes paralelos que ni siquiera se tocan: el orden natural donde encontramos al hombre viviente, al animal político, a la persona humana, y el orden jurídico, construcción meramente artificial y sin contenido real. Si esto fuera así, preguntamos: ¿qué tiene realmente que ver el derecho con la vida política, económica y social de los hombres? $\mathrm{Y}$, si efectivamente tiene que ver, entonces habría que explicar cómo se produce esta relación entre dos órdenes del mundo que poseen naturalezas tan distintas. Con razón sostiene I. M. Hoyos que "La doctrina civilista contemporánea reconoce la insuficiencia de la noción elaborada por la ciencia del derecho para definir jurídicamente a la persona con base en los conceptos cívico-jurídicos de estado, derechos subjetivos, y capacidad". Y agrega: "Cada día se advierte con más insistencia la necesidad de estudiar el concepto de

15 Tratato di diritto civile italiano. Athenaeum, Roma, 1921, pp. 443 y ss.

16 Tratado general de filosofía del derecho. Porrúa, México D.F., 1983, p. 263. 
persona con base en el concepto filosófico de persona”. ${ }^{17}$ De la misma idea es Hernández Gil quien, según la autora citada, sostiene que no es posible la construcción de una teoría solamente jurídica de la persona, ya que ésta no empieza a ser o existir con el derecho. El derecho reconocería solamente significación a lo que existe con validez y realidad anterior. Por eso, explica Legaz y Lacambra, ${ }^{18}$ el problema jurídico de "persona" posee el interés intrínseco de constituir uno de los temas más importantes de la ciencia y la filosofía del derecho. Si eso es así, resulta más convincente asumir la teoría realista que sostiene que hay una clara interrelación entre los conceptos filosófico y jurídico de persona. Así lo asumió también el derecho internacional de los derechos humanos que, en sentido general, reconoce y declara que todos los hombres son personas.

\section{v) La reconstrucción del concepto de "persona" en el realismo metafísico}

En saber dar a cada uno lo suyo residía, para los juristas romanos, la esencia del arte del derecho. ${ }^{19}$ Así como Aristóteles induce sus ideas de justicia observando cómo se comportan los hombres en el tráfico de la poli, los juristas romanos no inventaron ni construyeron los conceptos jurídicos a priori. A lo que correspondía a cada uno lo llamaron el ius, o derecho de cada uno, y a la ciencia que consistía en saber averiguar el ius le dieron el nombre de ars iuris, o arte del derecho. "Este ius, dice Javier Hervada, ${ }^{20}$ era lo justo, lo que justamente -lo que por obligación y en la justa medida, ni más ni menos- era atribuible a cada uno. Y la virtud de obrar así constantemente se llamaba iustitia o justicia. Ésta, pues, era considerada como la virtud de dar a cada uno lo que le correspondía, medida estricta, o sea, la perpetua y constante voluntad de dar a cada uno lo suyo (su ius, su derecho). Ius suum cuique tribue”. Se ve de inmediato en este esquema de los juristas romanos la descripción de la realidad social. El ver lo que corresponde a otro y entregárselo, es algo propio de la razón práctica, una virtud llamada prudencia. Prudencia en el derecho, iuris prudentia, da por resultado la expresión jurisprudencia.

El dar a cada uno lo suyo exige dos acciones: conocer y querer. El conocimiento permite saber a quién hay que dar lo suyo, y la voluntad se expresa mediante el acto de querer. Y si se quiere constantemente dar a cada cual lo suyo (la voluntad constante y perpetua), entonces hay una disposición, es decir, una inclinación del espíritu a actuar siempre de la misma manera. Dar a cada uno lo suyo es una necesidad social y si así se obra, se contribuye a la armonía y a la paz. De modo que dar a cada cual lo suyo es

17 Op. cit., p. 37.

${ }^{18}$ Cf. "La noción jurídica de la persona humana, los derechos del hombre". Revista de Estudios Políticos, vol. IX, 1951, p. 15.

${ }^{19}$ Kelsen considera que introducir el "concepto irracional” de justicia en la ciencia jurídica y considerarlo como pieza clave del derecho, es una tarea inútil y anticientífica porque equivale a introducir elementos emocionales en el derecho, tal como erróneamente ha hecho históricamente, en su opinión, la teoría del derecho natural. Cfr. Teoría general del derecho y del Estado. UNAM, México D.F., 1979, pp. 6 y ss.

${ }^{20}$ Op. cit., p. 16. 
apetecible y bueno en sí mismo. Es un hábito bueno, es decir, una virtud. Esta virtud ${ }^{21}$ se llama justicia. "La justicia no tiene otra medida que la dignidad del hombre, la condición de persona, en la que se fundamenta todo derecho posible". ${ }^{22}$

La persona, precisamente por reunir los atributos exclusivos de los que hemos hablado anteriormente, posee un dominio o señorío, en primer lugar, sobre su propio ser y, luego, sobre las cosas que le pertenecen, sean éstas reales o abstractas. La persona está, entonces, capacitada para perseguir y alcanzar sus propios fines que lo deben conducir a la plenificación y desarrollo de sus potencias intelectuales y espirituales. Este dominio se manifiesta de manera preferencial en aquellas cosas de las que es titular por naturaleza, no por voluntad de los hombres, esto es, sus derechos naturales.

Como se podrá observar, en este discurso se ha deslizado la expresión "naturaleza", y otras más de carácter metafísico, dando a entender con ello que la persona humana crea en sí misma y por sí misma una cierta realidad radical fundante que es fuente de vida y movimiento, y que es a lo que, justamente, Aristóteles llamó physis y los latinos tradujeron por naturaleza. Y dado que este concepto es decisivo para la correcta intelección y explicación de esta teoría jurídica, conviene que nos detengamos, brevemente, en la explicitación de éste y otros conceptos aristotélicos -y luego tomistas- para observar cómo se integran y contribuyen a solventar una idea de persona como realidad radical y jurídica a la vez.

Si en presencia de un ente concreto, por ejemplo, Calias, se dice que tengo frente a mí a un hombre, se indica lo que la cosa es y, con ello, se significa una sustancia. "Hombre", en consecuencia, puede decirse de dos modos, según el Estagirita: como ousía, en un sentido preciso y "concreto", por decirlo así, y como ousía, en sentido formal y abstracto. Al primer modo de decir, Aristóteles lo llamó sustancia primera o sustancia propiamente tal; al segundo, sustancia segunda. Si decimos "el hombre es un animal racional”, estamos diciendo que a un ente genérico y formal ("hombre”) le convienen los predicados esenciales y universales de "racionalidad" y de "animalidad". Pero si decimos de Calias que es un "hombre", estamos afirmando de una sustancia primera (que existe individualmente) que "cae", como dicen los lógicos, dentro del predicado o concepto universal "hombre". Y como Aristóteles considera que la existencia es una perfección del ser, entonces Calias, en tanto sustancia propiamente tal, es un ente más perfecto que el mero ente de razón o universal "hombre".

Permítasenos adentrarnos un poco más en la idea de "naturaleza" o "physis", por cuanto de la correcta intelección de este concepto dependerá, también, una adecuada comprensión del papel que le corresponde desarrollar al hombre en su vida personal y comunitaria. En efecto, ¿qué queremos decir exactamente cuando hablamos de "naturaleza"? En primer lugar, con el adjetivo "natural” predicamos algo del ser que le pertenece en sí y por sí, y que no le ha sido agregado por transformación artificial o convencional. Lo

${ }^{21}$ Cf. Tomás de Aquino, De las virtudes. Introducción y nota de Antonio Amado Fernández. Universidad de los Andes, Santiago de Chile, 1997. Cf. igualmente de Reyes Olibe, B.E., La voluntad del fin en Tomás de Aquino, ediciones Vórtice, Buenos Aires, 2004.

22 Op. cit., p. 38. 
natural es, entonces, contrario a lo artificial, a lo espiritual y a lo sobrenatural. Aristóteles sostuvo que hay varios modos de entender el concepto de "physis": el elemento primero de donde emerge lo que crece; el principio del primer movimiento inmanente en cada uno de los seres naturales en virtud de su propia índole; el elemento primigenio de que está hecha una cosa o de la cual proviene la realidad primera de la cosa (Metafísica, IV, 101 4b, 16-1015 a 12). De aquí parece seguirse que, por naturaleza, el Estagirita comprende el principio del ser y, más precisamente, la naturaleza que equivaldría a la esencia de los seres que poseen en sí mismos y en cuanto tales el principio del movimiento. De todo ello se sigue que la naturaleza de una cosa es lo que hace que la cosa sea un ser y, por consiguiente, un llegar a ser a través de un movimiento que le es propio. Y, por eso, lo que es por naturaleza se contrapone a lo que es por otras causas. La naturaleza también orienta al ser en un sentido y dirección determinados.

Explicadas estas ideas, aunque sea imperfectamente, hemos de ponerlas ahora en relación con el par ordenado de ideas aristotélicas de potencia (dínamis) y acto (enérgeia). Cuando Aristóteles se enfrentó con el eterno problema del movimiento que habían tratado de explicar infructuosamente los presocráticos y el propio Platón, el maestro del Liceo explicó que el movimiento consiste en el paso gradual y ordenado, conforme a la naturaleza de los entes, de la potencia al acto. Los seres vivos, por ejemplo, son de distinta manera según el momento que les toca vivir. La semilla de la bellota es semilla de bellota, como realidad actual, pero es también potencialmente una encina. No es encina, pero sólo ella puede llegar a serlo porque, efectivamente, también es encina, aunque en potencia. Ninguna otra semilla sino la de la encina puede, bajo determinadas condiciones y circunstancias, desarrollar las potencias que tiene dormidas para llegar a ser un cierto día, encina.

Ahora, tendríamos que preguntarnos, una vez más, acerca de la potencia que es propia del hombre no en cuanto ser corpóreo sino en cuanto ser psicoespiritual y complejo intelectual; no en cuanto animal, sino en cuanto entidad que se empina y se erige por sobre la materialidad, aunque a partir de ella, necesariamente y sin abandonarla. La potencia propia del hombre, en el racionalismo griego y también tomista, sería la racionalidad. La racionalidad está en potencia en el niño y debiera llegar a desplegarse completamente en el adulto. O sea, que en la naturaleza de la especie está ínsita la racionalidad como un invariante o marcador esencial, sin el cual el hombre no puede ser, ni menos llegar a ser, hombre propiamente tal. Me refiero, como lo concebían los pensadores griegos, al hombre sin limitaciones en el pleno de sus capacidades que es, ciertamente, el ideal de hombre para una mente aristotélica o platónica.

Si el hombre responde, pues, a una naturaleza racional, es precisamente la racionalidad, y sólo la racionalidad, la que le permitirá desenvolverse "correctamente" en la vida moral y jurídica. Es decir, cuando el hombre actúa, lo hace siempre en un entramado de relaciones muy complejo de orden moral, político y jurídico. Lo moral, lo político y lo jurídico están, pues, inscritos en la naturaleza humana. Nadie puede evitar la vida moral, política o jurídica; estamos por naturaleza llamados a participar en ella. El solo hecho de no querer participar en ella es un modo de participar. Con razón la segunda definición que Aristóteles ofrece del hombre es de carácter político. Dice, 
en efecto, que el hombre es animal político por naturaleza. Al hombre le basta con su ser para ser, para perseverar en la existencia, pero no le basta su ser para participar en la vida práctica. Para esto último requiere actuar, desempeñar un papel, un rol, como el actor en el escenario. Requiere, pues, apersonarse, hacerse persona. Sólo se es o se llega a ser persona en la vida social y política -como sostendrán los filósofos griegos y la mayor parte de los pensadores medievales, los empiristas ingleses, Kant, Hegel y otros pensadores modernos- y no fuera de ella. Representar un rol es, en cierto modo, actuar, asumiendo una representación de sí mismo que no desvincula al representado del representante, y que permite participar del juego colectivo que estamos llamados a desempeñar en la red jurídica y social. Así, pues, pasamos del hombre a la persona y de la persona al sujeto de derecho, de suerte que se observa una línea metafísica no interrumpida entre hombre, persona y sujeto de derecho, que coordina coherentemente la realidad y la visión metafísica con la jurídica y social.

Sobre la base de estas ideas de cuño clásico, podríamos rediseñar una noción de "persona" que sea compatible con una idea de derecho integral superadora de la concepción formalista y positivista tal cual la presenta, por ejemplo, Kelsen. ${ }^{23}$ No hay ningún inconveniente, desde el punto de vista de la coherencia racional, en admitir una continuidad entre la idea ontológica y la idea jurídica de persona. Por el contrario, en la concepción jurídica y filosófica antigua y medieval la persona desempeña un rol en el derecho que no es independiente de su condición humana. Es la condición humana la que obliga, en definitiva, al hombre a aparecer en el mundo jurídico y social como persona para poder desplegar y desarrollar en ese mundo sus potencialidades que, en definitiva, le permitirán alcanzar la realización personal y la integración a la sociedad. Naturalmente que esto tuvo una serie de limitaciones empíricas y reales como, por ejemplo, la constitución de estratos o estamentos en la sociedad antigua o medieval. Pero ese es un problema histórico que no afecta en absoluto la idea filosófica y jurídica de un derecho fundado en la naturaleza humana y puesto al servicio de la persona. La idea de que hay en la persona un sustrato óntico, en el cual residen ciertos derechos que le vienen dados de antemano y que la convención jurídica y política debe reconocer y respetar, se transformará, en el curso de los siglos, en un principio que llegará a consagrarse en el mundo jurídico moderno y contemporáneo.

Ahora bien, el hecho de que la persona humana posea ciertos derechos inalienables, esenciales e inherentes a su naturaleza, no implica negar la posibilidad efectiva de que a partir de estos derechos se puedan derivar otros derechos de carácter positivo que la legislación humana debe regular y modular. Savigny expresa esta idea al responder a la pregunta 'quién es o puede ser sujeto de una relación jurídica' y explica que sólo

${ }^{23}$ Este autor se empeña en distinguir de una manera tajante al hombre como realidad empírica y sustancial, con vida racional y espiritual, de la mera "persona física" y sostiene que este último concepto, de carácter enteramente jurídico y formal, nada tiene que ver con el hombre en tanto realidad psíquica, biológica e histórica. Pero si fuere así, no habría cómo explicar de qué manera la norma jurídica y la decisión judicial afectan, realmente, a la persona, entendida en un sentido antropológico y filosófico radical. Por otro lado, no se ve cómo el hombre real pueda ser sólo el "contenido” de la norma jurídica y la decisión judicial si, como él afirma, "persona” ha de ser entendida sólo como un concepto formal e instrumental. 
puede serlo la persona, es decir, el ser que tiene la aptitud para poseer derechos. El hombre tiene naturalmente esa capacidad. La idea de persona o sujeto de derecho, por tanto, se confunde con la idea misma de hombre, de suerte que todo individuo y sólo el individuo de la especie humana tiene capacidad de derecho. Savigny reconoce que todo hombre tiene sobre sí mismo un derecho que nace con él y que se extingue con él. Este es un derecho originario, en oposición a los adquiridos, los cuales son de naturaleza pasajera. ${ }^{24}$

En el pensamiento del gran jurista alemán pareciera subyacer una idea que concilia el aspecto realista con el aspecto formalista del derecho, lo que, por lo demás, al parecer está en la línea correcta si se observa la evolución del derecho internacional de los derechos humanos y del constitucionalismo contemporáneo. La persona humana es, por naturaleza, un ser jurídico, del mismo modo que es un ente racional y moral. De esa naturaleza se deriva la titularidad sobre ciertos derechos que le son esenciales, como el derecho a la vida y el derecho a la libertad y, también, en su naturaleza se encuentran en potencia todas las condiciones necesarias y suficientes para desarrollar a plenitud sus capacidades humanas conforme a un concepto de bien que viene predeterminado por el mandato de la razón. Si se aceptan estos antecedentes, se podría concluir que la persona humana, en tanto sujeto de derecho, conlleva por naturaleza la titularidad de ciertos derechos esenciales y que la legislación humana le otorga la capacidad para adquirir derechos y contraer obligaciones de manera válida y efectiva.

En conclusión, podemos decir que el realismo metafísico clásico sostiene que, a partir del sustrato óntico, cree derivar en el hombre un núcleo de moralidad y de legalidad natural en la persona humana, fuente de las obligaciones morales jurídicas. ${ }^{25} \mathrm{Y}$ dado que el hombre está inclinado a realizar el proyecto que lleva ínsito en su naturaleza, se podría decir que una vida humana conducida por los dictados de la razón tiene que desembocar, necesariamente, en la perfección de las acciones morales y jurídicas que plenifican la vida personal y social de los hombres. También en la filosofía kantiana encontramos en la conciencia del deber la fuente de las obligaciones morales y jurídicas. "Sólo conocemos nuestra propia libertad (de la que proceden todas las leyes morales, por tanto, también todos los derechos así como los deberes) a través del imperativo moral, que es una proposición que manda el deber y a partir de la cual puede desarrollarse después la facultad de obligar a otros, es decir, el concepto de derecho". ${ }^{26}$

Si en el realismo metafísico clásico la naturaleza es el fondo último en el cual descansan los bienes humanos básicos y, a partir de ellos, se desarrollan conforme a los dictados de la razón para alcanzar el fin propio del hombre, que es el bien, en la filosofía kantiana

${ }^{24}$ Sistema de derecho romano actual. Centro Editorial de Góngora, Madrid, 1924. pp. 260 y ss.

${ }^{25}$ Según Tomás de Aquino, en el orden de la inteligibilidad “la mente capta previamente 'un ser'; en segundo lugar, se capta 'a ella misma siendo intelectiva con respecto a un ser'; y, en tercer lugar, se capta 'a ella misma siendo apetitiva con respecto a un ser'. En consecuencia la inteligibilidad 'un ser' viene primero, en segundo lugar viene la inteligibilidad 'lo verdadero' y en tercer lugar la inteligibilidad 'lo bueno'. S.Th., I, q.16, a.4, ad. 2. Así se funda entonces la ética de manera inmediata y sin solución de continuidad en la ontología.

${ }^{26}$ La metafísica de las costumbres. Tecnos, Madrid, 1994, p. 51. 
la conciencia del deber se transforma en la fuente de las obligaciones que determinan al sujeto jurídico y moral a actuar conforme a ellas. El hombre, en tanto realidad abstracta y general, se convierte en persona no sólo por su capacidad para construir un mundo íntimo y espiritual sino, fundamentalmente, porque es capaz de extraer de las fuentes de la racionalidad los mandatos que, conforme al deber, determinan su vida práctica. En otros términos, si en el realismo metafísico clásico -y también contemporáneo- la fuente de la obligación moral se encuentra, en último extremo, ínsita en la naturaleza humana, en Kant, en cambio, ésta es la manifestación más radical de la conciencia del deber. De este modo, más allá del hombre, como realidad abstracta y general, Kant distinguirá la persona como ente responsable y libre que es capaz de asumir derechos y obligaciones y actuar conforme a ellos por puro respeto al deber que se descubre y se revela inmediatamente a la conciencia racional. El dato clave y fundamental que define y determina a la persona como ente moral y jurídico es la libertad y, por eso, sostendrá este pensador que la libertad es el único derecho innato al que la persona está llamada, ${ }^{27}$ en virtud de su naturaleza racional, a desplegar en su vida privada y pública. A su vez, el Estado no tiene otra función que la de asegurar a la persona humana, mediante el derecho, la posibilidad de la coexistencia y de la total y plena realización de la individualidad conforme a las leyes universales de la libertad.

\section{vi) Una interpretación desde la teoría lógico-lingüística de Frege}

Finalmente, quisiéramos exponer nuestro argumento a favor de la teoría que sostiene que no hay una diferencia esencial entre el concepto filosófico y jurídico de persona, porque ambos conceptos responden y derivan, en último extremo, de una única realidad que es el hombre considerado espiritual, histórica y socialmente y sobre el que se funda y despliega la persona humana. Para esto hemos dicho que podríamos valernos de la teoría lógico-semántica que elaboró Frege a finales del siglo XIX, para explicar el estatus y la naturaleza de las entidades de razón que aparecen en el lenguaje ordinario. En primer lugar, de acuerdo a la teoría de Frege, habría que distinguir en todo nombre propio dos aspectos: el sentido (Sinn) y la denotación (Bedeutung). "El nombre propio (palabra, signo, conjunto de signos, expresión) - dice Frege- expresa su sentido, denota o designa su denotación. Mediante un signo expresamos su sentido y designamos su denotación". ${ }^{28}$ Cabe, pues, pensar que un signo va ligado, además de lo designado, a un sentido que Frege concibe como el modo de darse la denotación. Napoleón en persona es lo denotado por el nombre propio "Napoleón”. Pero "El militar más grande que ha tenido Francia” y "El emperador francés que fue derrotado por los ingleses en Waterloo"

${ }^{27}$ También H.L.A. Hart parece sostener que la libertad constituye un derecho innato. "Sostendré, escribe, la tesis de que si hay derechos en el campo moral, entonces se sigue de allí que hay por lo menos un derecho natural, a saber, el derecho igual de todos los hombres de ser libres". Derecho y Moral. Contribuciones a su Análisis. Versión de Genaro R. Carrió. Depalma, Buenos Aires, 1962, p. 65.

28 "Sobre sentido y denotación" ("Über Sinn und Bedeutung”) en Lógica y semántica. Versión de Alfonso Gómez Lobo, Valparaíso, Chile, 1972. p. 53. 
serían dos modos de darse de la denotación Napoleón o, lo que es lo mismo, dos sentidos diferentes del mismo nombre propio "Napoleón".

"El nombre propio -agrega Frege- debe tener por lo menos un sentido (tal como yo empleo la palabra), pues de lo contrario sería una sucesión de sonidos vacía, llamada nombre sin ningún derecho. Para el uso científico se debe exigir que tenga también denotación, que designe o nombre un objeto". ${ }^{29}$ A la luz de estas declaraciones de Frege, el nombre propio "El rey de España” sería diferente de la expresión "El rey de Francia" porque, obviamente, el primer nombre no sólo tiene un sentido sino, además, una denotación, mientras que la segunda expresión sólo posee sentido, pero no denotación. La denotación y el sentido de un signo deben distinguirse, a su vez, de la representación (Vorstellung) que suele unirse al signo. La representación no pertenece al signo, no forma parte de su significación, sino que es lo que éste sugiere a la mente de quien escucha y comprende un nombre. Por eso Frege dice que cuando la denotación de un signo es un objeto sensible, la representación que nos hacemos de él es una imagen interior que surge empapada de impresiones, recuerdos y experiencias personales que cada uno de nosotros tiene de modo individual y privado. Por eso, no siempre, y ni siquiera en una misma persona, la misma representación está ligada al mismo sentido. A Frege le interesa dejar bien claro qué es lo que ha de entenderse por representación para evitar confundir la representación con el sentido, el cual concibe como algo totalmente objetivo. Los sentidos pertenecerían a una especie de realidad supraobjetiva, independiente, por tanto, de la realidad empírica y de la realidad psíquica.

Explicada brevemente la teoría de Frege, podríamos intentar aplicarla a las expresiones lingüísticas propias del derecho y de la filosofía jurídica. Respecto de la expresión “persona” podríamos decir, siguiendo la teoría de Frege, que tiene dos sentidos diferentes pero una sola denotación. La denotación sería el núcleo ontológico radical (la sustancia) que soporta al hombre individual como ser existente en la realidad histórica y social. Esa realidad ha sido llamada "homo", "persona", "individuo" en la historia del pensamiento jurídico occidental.

La filosofía analítica contemporánea ha puesto de relieve que el uso correcto del lenguaje es fundamental para distinguir entre las expresiones que efectivamente denotan una realidad y aquellas que sólo aparentan hacerlo. Se puede perfectamente hablar de "el rey de Francia", y precisamente porque podemos hacerlo, quienes no estuvieren informados de que no hay rey en Francia, podrían pensar que efectivamente lo hay por el solo hecho de que existe la expresión que lo nombra. Desde este punto de vista, habría que distinguir en cualquier palabra o expresión al menos cuatro aspectos: el nombre, la representación mental, el concepto objetivo (o sentido) y la denotación o referencia. El nombre es simplemente el conjunto de sonidos gramaticalmente articulados, o de fonemas correctamente ordenados conforme a las reglas de una lengua. La representación mental sería la imagen interior que los hablantes se hacen a partir del nombre que escuchan o leen, mientras que el sentido o concepto sería la construcción que la razón

\footnotetext{
${ }^{29}$ Op. cit., p. 53.
} 
hace de los datos que le entregan la percepción y la sensación. Finalmente, la denotación sería el objeto mismo.

Consideremos, por ejemplo, la expresión "hombre" y veamos qué se quiere significar cuando esta palabra es empleada en una oración o discurso. Desde luego es un nombre, pero cada cual se hace una representación o imagen mental singular que no coincide, necesariamente, en distintas personas. En tercer lugar, nadie negará que la expresión "hombre" tiene también un sentido, es decir, una cierta concepción universalmente aceptada acerca de este tipo de entidad. Hasta aquí habría un acuerdo general pero, a continuación surgirá, sin duda, una divergencia. Para algunos, el nombre "hombre" designa (hace "referencia" o "denota") únicamente una idea, un concepto general y abstracto -es lo que se llama en la filosofía medieval un "universal"-, mientras que para otros la palabra hace referencia a los diversos individuos que responden a este nombre y que comparten ciertos atributos generales. Otros, en fin, sostendrían que la palabra designa una suerte de realidad óntica, independiente de la mente que la percibe y conceptualiza. Ahora bien, si la palabra "hombre" aparece en una expresión como "el hombre es un animal racional y bueno", uno podría preguntarse, de acuerdo a esta teoría, si quien profiere esa expresión está haciendo una referencia a una realidad que existe y subsiste en sí misma y por sí misma (realidad metafísica), más allá de la mente de quien la enuncia y de quien escucha, o si sólo se está refiriendo a un concepto general y abstracto (un "universal") o, por último, si simplemente se refiere a los individuos empíricamente individualizados en la realidad temporeoespacial. Lo más razonable pareciera ser que cuando las personas utilizan esta palabra o expresión, es para referirse a los individuos de la especie humana que circulan por el mundo e intervienen en la vida social. El lenguaje descubre su objeto.

Y, mutatis mutandi, lo mismo podríamos decir del concepto de "persona". Cuando hablamos de "persona" entendemos naturalmente que la palabra formaliza un concepto y que este concepto, a su vez, hace referencia al hombre ("homo"). Pero se puede hacer referencia a la persona de varias maneras, según el contexto del que se trate. Si se trata del lenguaje coloquial, fácilmente nos damos cuenta que con esa expresión estamos haciendo referencia o denotando el tipo de entidades humanas vivientes y capaces de reflexionar y construir una vida íntima y espiritual. Si usamos la palabra, en cambio, en un contexto religioso, también percibimos enseguida que estamos haciendo referencia a un ente que, en virtud de sus capacidades, creencias y vida espiritual, cree estar en condiciones de elevarse a la vida eterna y acceder a Dios. Si la usamos en un sentido filosófico, estamos destacando los atributos de la libertad y de la voluntad. Y si en un contexto jurídico alguien asevera que tal persona no ha cumplido con las obligaciones emanadas de un contrato, seguramente entenderemos que estamos refiriéndonos a un individuo de la especie humana (conforme al art. 55 del Código Civil chileno) que, en tanto sujeto de derecho, no ha cumplido con una disposición emanada de la voluntad de los contratantes.

Entonces podríamos sostener que entre estas diversas maneras de "decir" la palabra "persona" existe una comunidad semántica que permite identificar y, a la vez, diferenciar los respectivos conceptos o sentidos según el ámbito cultural en el que se emplean. Lo 
que pretendemos sostener es que, efectivamente, todas estas expresiones hacen una única referencia o denotan la misma realidad a pesar de los sentidos diferentes que sus contextos les confieren. Ejemplifiquemos esto con un caso tomado del propio Frege. Según el autor alemán, las expresiones "el lucero de la mañana” y "el lucero de la tarde" tienen muy distinto sentido y, sin embargo, tienen la misma denotación, esto es, el planeta Venus. Es decir, que la realidad (con consistencia propia) Venus es una y la misma, pero se da o aparece con dos sentidos distintos según el contexto en el que se use. Pero nadie podría razonablemente sostener, a no ser por ignorancia, que ambos sentidos no tienen parentesco alguno, sea porque no hay una denotación que les otorgue significado, sea porque se refieren a realidades distintas.

En nuestra opinión, el uso filosófico y el uso jurídico de la expresión "persona” hacen referencia a una sola y la misma realidad, esto es, a los hombres de carne y hueso que han existido a lo largo de la historia y que existen en la actualidad. Pero lo dicen en sentidos diversos. En el primer caso, el sentido primordial está relacionado con la capacidad que tiene este animal viviente de conocerse y conocer el mundo racionalmente y actuar conforme a su libertad y voluntad. En cambio, en el contexto jurídico, el sentido prevalente es el de un individuo de la especie humana que, en virtud de sus capacidades intelectuales y volitivas, es titular de derechos y obligaciones, y está capacitado para responder, según lo establece el ordenamiento jurídico, por sus actos que contrarían la ley.

Si nos dejamos guiar por el uso que hacemos de la lengua, entonces deberíamos concluir que la expresión "persona” en el uso jurídico y filosófico tiene dos sentidos distintos aunque una misma denotación, puesto que está refiriéndose a los individuos de la especie humana.

A la luz de estas consideraciones pensamos, en definitiva, que es razonable y legítimo sostener que el concepto de persona encuentra su fundamento último en una realidad humana, tal como esta se da a través de los diversos individuos que han existido y existen en la realidad. Y si es así, entonces habría que admitir que entre el concepto filosófico y el jurídico de persona hay una relación sin solución de continuidad, que vincula y coordina de manera coherente el uso jurídico y el filosófico de este concepto.

\section{CONCLuSiones}

Recordemos que nuestro punto de partida estaba motivado por una problemática que se da en el mundo de la filosofía y la teoría del derecho, problemática según la cual para algunos - positivistas- no existiría una relación o vinculación necesaria entre el concepto jurídico de persona y el concepto filosófico-antropológico de ésta; para otros, ocurriría todo lo contrario: habría una relación de continuidad entre el concepto filosófico y el concepto jurídico de "persona".

Comenzamos explicando que inscribiríamos nuestra investigación en el amplio contexto del realismo metafísico para pasar, después, a la filosofía práctica de Kant y, finalmente, aplicar los hallazgos de la filosofía fregeana en el análisis de este complejo problema jurídico-filosófico. 
En la primera parte nos dedicamos a desarrollar el concepto de persona desde sus orígenes grecolatinos, aristotélicos y cristianos, destacando el rol esencial que en esta concepción juegan el concepto filosófico de "naturaleza" y la idea antropológica de "intimidad”, característica de la nueva cosmovisión cristiana. La idea central que resultó del análisis muestra que efectivamente se puede hablar de una suerte de invariante o constante óntica que los aristotélico-tomistas han llamado esencia o naturaleza humana. Según este punto de vista la persona humana encuentra su fondo último de realidad y de consistencia óntica en la idea de "humanidad" y la humanidad es lo que caracteriza al hombre en tanto hombre, es decir, en su dimensión de ser racional, libre y capaz de construir su propia intimidad.

La filosofía kantiana entiende al hombre como un ente racional capaz de autodeterminar sus acciones conforme a un profundo sentido del deber que constituye la conciencia moral, fuente de las obligaciones éticas y jurídicas. A este "hombre", así determinado, Kant lo llama "persona”.

Tanto en la filosofía aristotélico-tomista como en la filosofía práctica de Kant hay un fondo metafísico que en último extremo sostiene la idea de "hominidad" y que hace surgir, a partir del ser humano, la "persona”, que origina, en definitiva, el florecimiento o epifanía de la "hominidad".

Esta sería una manera de explicar la relación continua entre el concepto filosófico y el concepto jurídico de persona. Finalmente, lo que daría unidad a ambos conceptos sería la hominidad que subyace en el homo y que se manifiesta de manera distinta en el hombre tomado como una realidad filosófico-antropológica (persona en sentido filosófico) y el hombre visto como una realidad jurídica (persona en sentido jurídico).

A nuestro modo de ver, esta explicación filosófica, en general, no es lo suficientemente fuerte como para desestimar la idea positivista de persona que sostienen autores como Kelsen. No alumbra todo lo que se quisiera, sobre todo en el ámbito del derecho civil. La tercera concepción que hemos integrado a nuestra visión del problema tiene la ventaja de contribuir de una manera meramente metodológica a escudriñar y tratar la cuestión. Frege enfoca el problema de la diferencia entre el sentido y la denotación (o significado) recurriendo a una concepción y a una metodología lógico-lingüística. Primero parte de la idea fácilmente intuible y comprobable de que los nombres y sus expresiones hacen o pretenden hacer referencia. Legítimamente hablando, sólo las expresiones que hacen referencia tienen significado. Si una expresión no hace referencia, podrá tener sentido pero no significado, como cuando se dice "Odiseo fue desembarcado en Itaca profundamente dormido”. Nadie duda que la expresión literaria citada tiene pleno sentido, pero nadie pretendería, además, que esa expresión hace referencia, razón por la cual Frege diría que no tiene significado (Bedeutung), en sentido estricto. Al tratar de aplicar esta conceptualización filosófica al problema que nos preocupa creemos haber puesto de relieve que la expresión "persona” adquiere diversos sentidos según el contexto en el que se la utilice. Puede tener un sentido jurídico, por ejemplo, civil, si se trata de sujeto de derecho y obligaciones contractuales; puede tener un sentido constitucional o internacional público cuando se habla de los derechos universales de la persona humana; pero también tiene un sentido incluso preliminar cuando se habla simplemente de la 
persona entendida como un sujeto moral, político o social que, en una determinada circunstancia, juega un rol dentro de la sociedad de la cual forma parte. Sin embargo, no cabe duda que tanto el sentido filosófico general como el jurídico encuentran un fundamento posibilitante en el concepto de "hombre" ("homo"), que es de dominio lingüístico general y por intermedio del cual los individuos hacen referencia a cierto tipo de entidades animales capaces de pensar, querer y decidir libremente conforme a sus convicciones y creencias.

De esta manera no parece necesario recurrir a entidades metafísicas, al menos en este nivel del uso del discurso, para mostrar que entre el concepto filosófico y el jurídico de persona hay una referencia o denotación común -que son los hombres mismos- que permite explicar el parentesco sólido de ambos conceptos.

\section{BIBLIOGRAFÍA}

Abbagnano, N., Diccionario de Filosofía. Fondo de Cultura Económica. Buenos Aires, México, 1982.

Beochut, M., "Naturaleza humana, ley natural como fundamento de los derechos humanos", en El iusnaturalismo actual, Massini-Correas, C.I. (ed.).

Cofré, J.O., "Las reglas óptico-constitutivas, Fundamentos de la Persona y la Dignidad Humana". Revista de Derecho. Universidad Austral de Chile, vol. XV, diciembre 2003.

Cofré, J.O., "Los términos "dignidad” y “persona”. Su uso moral y jurídico. Enfoque Filosófico". Revista de Derecho. Universidad Austral de Chile, vol. XVII, diciembre 2004.

De Aquino, T., De las virtudes. Introducción y nota de Antonio Amado Fernández. Universidad de los Andes, Santiago de Chile, 1997.

Demogue, R., Traité des Obligations en général. 7 vols. Paris, 1923-1933.

DíAz, E., "Persona" en 10 Palabras claves en Ética. Adela Cortina (ed.). Editorial Verbo Divino, Navarra, 1994.

Fassó, G., Historia de la filosofía del Derecho. Ediciones Pirámides, S.A., Madrid, 1982. Vol. 1, 2.

Ferrara, F., Trattato di diritto civile italiano. Athenaeum, Roma, 1921.

Finnis, J., Natural Law and Natural Rights. Clarendon Press, Oxford, 1984.

Frege, G., "Sobre sentido y denotación" ("Über Finn und Bedeutung”), en Lógica y semántica. Versión de Alfonso Gómez Lobo, Valparaíso, Chile, 1972.

Hart, H.L.A., Derecho y Moral. Contribuciones a su Análisis. Versión de Genaro R. Carrió. Depalma, Buenos Aires, 1962.

Kant, I., Crítica de la razón práctica. Espasa Calpe, Madrid, 1965.

KANT, I., La metafísica de las costumbres. Tecnos, Madrid, 1994.

Kelsen, H., Teoría pura del derecho. UNAM, México D.F., 1981.

Kelsen, H., Teoría general del derecho y del Estado. UNAM, México D.F., 1979.

Hervada, J., Introducción crítica al derecho natural. Edit. EUNSA, 10ª edición, Pamplona, 2001.

Hoyos, I.M., De la dignidad y de los derechos humanos. Editorial Temis, Bogotá, 2005.

Legaz y LaCAmbra, L., "La noción jurídica de la persona humana, los derechos del hombre". Revista de Estudios Políticos. Vol. IX, 1951.

Massini, C.I., El iusnaturalismo actual. Abeledo, Perrot, Buenos Aires, 1996. 
Massini, C.I., El derecho natural y sus dimensiones actuales. Rodolfo Depalma, Buenos Aires, 1999.

RABBi-BALDI, R. (ed.), Las razones del derecho natural. Perspectivas teóricas y metodológicas ante la crisis del positivismo jurídico. Rodolfo Depalma, Buenos Aires, 1998.

Recaséns Siches, L., Tratado general de filosofía del derecho. Porrúa, México D.F., 1983.

Reyes Olibe, B.E. La voluntad del fin en Tomás de Aquino. Ediciones Vórtice, Buenos Aires, 2004.

San Agustín, De Trinitate, VII, 6. Cf. Ferrater Mora, J. Diccionario de Filosofía, Alianza Editorial, Madrid, 1982. Vol. 3.

SAvigny, K., Sistema de derecho romano actual. Centro Editorial de Góngora, Madrid, 1924.

SpaEmann, R., Lo natural y lo racional. Rialp, Madrid, 1989.

Spaemann, R., Personas: acerca de la distinción entre algo y alguien. EUNSA, Pamplona, 2000. 